\title{
Medication Safety in Patients under 18 Years Old; a Retrospective Study based on Iraqi Pharmacovigilance Center Database \\ Hani Gh. Jawad ${ }^{*, 1}$ Eman S. Saleh ${ }^{* *}$, Manal M. Younus***
}

* Ministry of Health and Environment, Medical City, Gastroenterology and Hepatology Specialized Hospital, Baghdad, Iraq. ** Department of Clinical Laboratory Science, College of Pharmacy, University of Baghdad ,Baghdad, Iraq.

${ }^{* * *}$ Head of Iraqi Pharmacovigilance Center, Directorate of Technical Affairs, Ministry of Health, Baghdad,Iraq.

\section{Abstract}

Medication safety is an important part of the comprehensive patient safety term. Medication safety is gaining more attention as the World Health Organization set the goal of decreasing medication harm by (50\%) for the next 5 years when launching the third global challenge. Studying medication safety in the risk groups such as young ages, children are crucial to learn more about the effect of medicines in this risk group since they are not included in the clinical trials. Adverse drug reaction is defined as any harm resulted from the drug itself during medical process journey, while medication errors are any harm resulted from the treatment process rather than the drug or it is the result of the failure in a step of the treatment process and by that it came clear that adverse drug reaction in non-preventable event while medication error is preventable one. The objectives of this study are to find the preventable medication errors from the Iraqi database of Adverse drug events in ages from neonatal to adolescent age. This study is a retrospective descriptive study conducted using the Iraqi pharmacovigilance center database. The study included reports that were received by the Iraqi pharmacovigilance center from $1^{\text {st }}$ of January 2014 until the $1^{\text {st }}$ of January 2020. In this study, the total number of reports included was 2344 . The type of medication involved, type of adverse event, type of error and phase of error were reviewed. The results show that $(50.47 \%)$ of the adverse event following administrating medication to the pediatric population were medication errors while adverse drug reaction represented the remaining (49.53\%). The prescribing phase was the one of greatest error $(59.43 \%)$ and the least one was dispensing $(0.17 \%)$. Most reports were general skin and subcutaneous tissue. The most common type of encountered error was self-medication with the non-over-the counter drug by (44.28\%). The result of the present study revealed that medication errors contribute significantly to adverse drug event among patients under 18 years old. This study highlights the importance of monitoring medication safety specifically in the risk groups.

Keywords: Medication errors, Adverse drug reaction, Medication safety, Iraqi pharmacovigilance center, Pediatric.

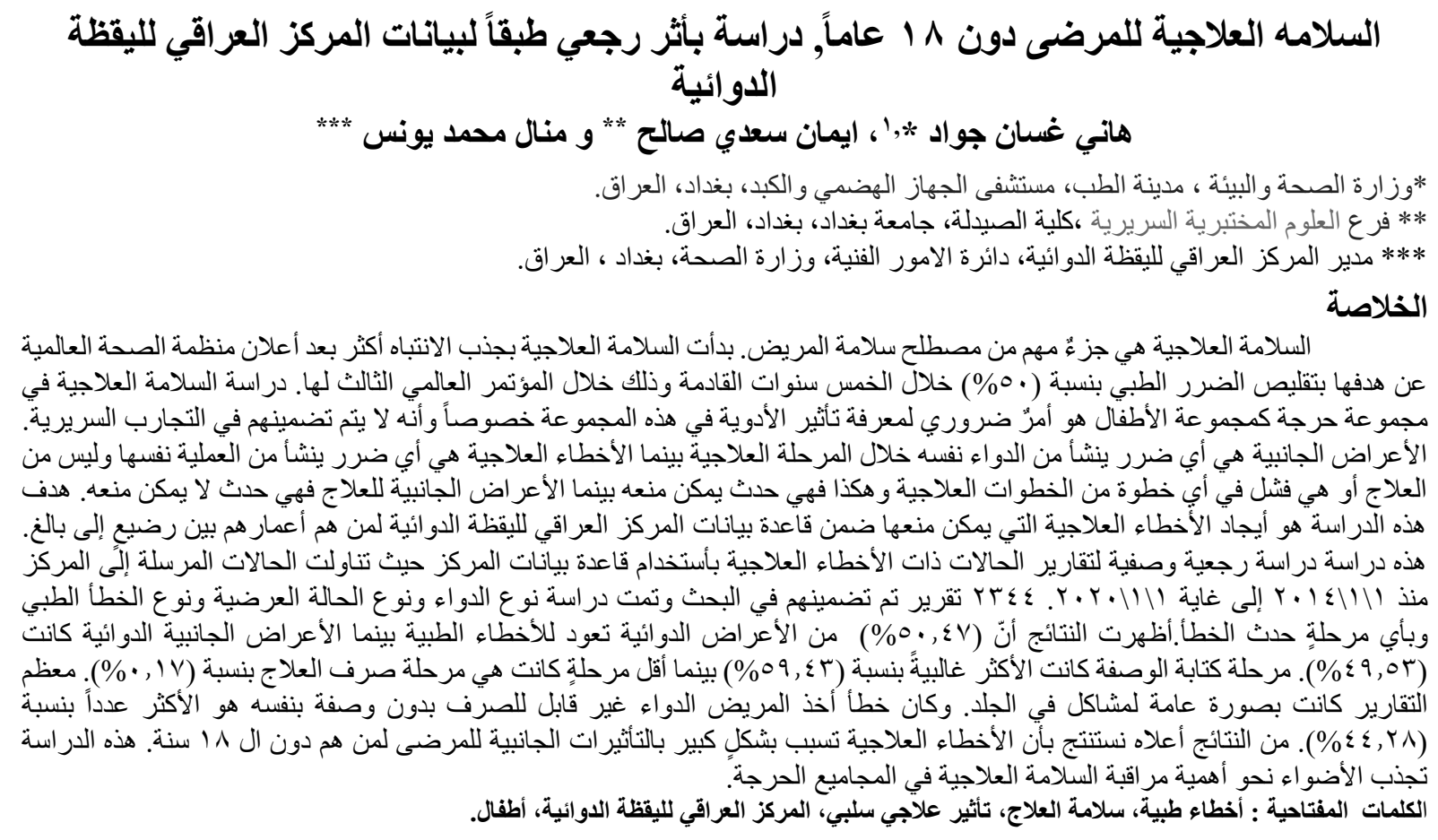

${ }^{1}$ Corresponding author E-mail: hani.pro55@gmail.com

Received: 5/3/2020

Accepted: 14/6/2020

Iraqi Journal of Pharmaceutical Science 


\section{Introduction}

Medication safety is a crucial part of any medical management and any adverse event that is preventable could compromise it. Medication safety is the application of various strategies in order to reduce the occurrence of adverse drug events during any stage of the medical process. Medication safety is an umbrella term that involves both Medication Error (ME) and Adverse Drug Reaction (ADR). Medication safety may also refer to Adverse Drug Event (ADE) which is defined as any harm that occurs during providing health services to patients regardless to the complexity of the disease and by that the definition of both (ME) and (ADR) become clear. ADR is defined as any harm resulted from the drug itself during medical process journey, while ME is any harm resulted from the treatment process rather than the drug or it is the result of the failure in a step of the treatment process and by that it came clear that ADR in non-preventable event while ME is preventable one ${ }^{(1)}$. One study in England indicates that ME cost up to $£ 750$ million yearly and its one of the most encountered ADE with a great potential to cause patient harm ${ }^{(2)}$. Ghadah. et. al, did a systematic review on the epidemiology of $\mathrm{ME}$ worldwide and concluded that the incidence of preventable ADEs was estimated to affect 15 people from every 1000 people yearly and that the prevalence of preventable ADE as $(0.4 \%){ }^{(3)}$. Errors that happened but didn't reach the patient are called "near misses", "close calls" and "potential ADE". Accordingly, not all medication errors cause harm, some are harmless and some do not reach the patient "near misses" (4). In order to detect and reduce the incidence of these ADE, every country must establish its own pharmacovigilance system. According to World Health Organization (WHO), pharmacovigilance is defined as "the science and activities relating to the detection, assessment, understanding, and prevention of adverse effects or any other medicine-related problem" (5). One of the most priority of each pharmacovigilance system is to develop systems that identify and rule out the root cause of medication error and how to decrease its incidence ${ }^{(6)}$. Most agencies categorize the treatment process into 4 phases which include: prescribing, dispensing, administering and monitoring ${ }^{(1)}$. Each error must be located in only one of these phases to be identified and corrected in the future and it is a sequence process as one error may lead to the subsequent error also, but for example, if the error started in the prescribing phase and lead to other errors in dispending and other phases, then the fault one must be attributed to prescribing only (1). Pediatric patients are prone to medication error at a higher rate than adult patient, this may be attributed to age difference between them and the wide difference in weight between them which make urge to calculate specific dose for each patient individually based on their own weight ${ }^{(7,8)}$. The objective of this study was to measure the prevalence of medication errors, which gender and age group affected more, and at which phase did the medication error occurs (Prescribing, Dispensing, Administration, Monitoring) in patients under 18 years depending on the Individual Case safety Reports (ICSR) data base of the Iraqi Pharmacovivelence Center.

\section{Methods}

This study is a retrospective descriptive study for identifying medication error cases among the reports that contain ADE reported to the Iraqi Pharmacovigilance Center from 1st of January 2014 until the 1st of January 2020. Official approvals were obtained from the authorities of the University of Baghdad College of Pharmacy, the Iraqi Ministry of Health and Iraqi pharmacovigilance center prior to the start of the study in order to get an account and $\log$ in access to the database of the center. VigiFlow was used in order to extract the data of reports received to the center. VigiFlow is a data management system created by the Uppsala Monitoring Center (UMC). The data of ADE were collected, identified and studied. Inclusion criteria are any ADE case reports for patients under 18 years old and include the use of medicines, herbals, and complementary medicines. Exclusion Criteria were reports of adult patients and the reports of vaccines (9). In order to distinguish between cases of ADR from ME, the P method was implied. The P method is adopted by WHO and it is based on several factors that if met, means that the case is a medication error case and it is preventable. Factors included 20 criteria that are related to various personnel involved in the treatment process. From these criteria 1 to criterion 16 are related to health care providers, criteria 19 and 20 are related to the patient himself while criteria 5, 6, 17 and 18 are related to drug product quality. The criteria 5 and 6 are related to both health care providers and drug product quality. The P method requires answering by "yes" whenever one of the criteria is met and that case would be medication error case and it is preventable which means that the root cause for error is known and it can be corrected in the future, or answering by "No" Whenever none of the criteria is met which implies that the case is ADR case and it is nonpreventable, or by answering "unknown" when the data available is not enough to assess the situation and by answering "not assessable" means that the case does not fit for the criteria to be decided on. The "unknown", "not assessable" will not be detected in this type of study, as the data available does not help in distinguishing these types of answering and this is summarized in Table 1 below ${ }^{(1)}$. 
Table 1. Criteria for the assessment of the preventability of $\operatorname{ADEs}^{(1)}$.

\begin{tabular}{|c|c|c|c|c|c|}
\hline $\begin{array}{l}\text { Factors } \\
\text { related to }\end{array}$ & Preventability criteria & Yes & No & UK & NA \\
\hline \multirow{16}{*}{$\begin{array}{l}\text { Professional } \\
\text { practice "Pr" }\end{array}$} & 1. Incorrect dose? & & & & \\
\hline & 2. Incorrect drug administration route? & & & & \\
\hline & $\begin{array}{l}\text { 3. Incorrect drug administration } \\
\text { duration? }\end{array}$ & & & & \\
\hline & $\begin{array}{l}\text { 4. Incorrect drug dosage formulation } \\
\text { administered? }\end{array}$ & & & & \\
\hline & 5. Expired drug administered? & & & & \\
\hline & 6. Incorrect storage of drug? & & & & \\
\hline & $\begin{array}{l}\text { 7. Drug administration error (timing, } \\
\text { rate, } \\
\text { frequency, technique, preparation, } \\
\text { manipulation, mixing)? }\end{array}$ & & & & \\
\hline & 8. Wrong indication? & & & & \\
\hline & $\begin{array}{l}\text { 9. Inappropriate prescription according } \\
\text { to } \\
\text { characteristics of the patient (age, sex, } \\
\text { pregnancy, other)? }\end{array}$ & & & & \\
\hline & $\begin{array}{l}10 . \text { Inappropriate prescription for } \\
\text { patient's } \\
\text { clinical condition (renal failure, } \\
\text { hepatic } \\
\text { failure ...), or underlying pathology? }\end{array}$ & & & & \\
\hline & $\begin{array}{l}\text { 11. Documented hypersensitivity to } \\
\text { administered drug or drug class? }\end{array}$ & & & & \\
\hline & 12. Labeled drug-drug interaction? & & & & \\
\hline & $\begin{array}{l}13 . \quad \text { Therapeutic duplication? } \\
\text { (prescription } \\
\text { of } 2 \text { medicines or more with similar } \\
\text { ingredient) }\end{array}$ & & & & \\
\hline & 14. Necessary medication not given? & & & & \\
\hline & $\begin{array}{l}\text { 15. Withdrawal syndrome? (due to } \\
\text { abrupt discontinuation of treatment) }\end{array}$ & & & & \\
\hline & $\begin{array}{l}\text { 16. Incorrect labora tory or clinical } \\
\text { monitoring of medicine? }\end{array}$ & & & & \\
\hline \multirow{2}{*}{$\begin{array}{l}\text { Product/drug } \\
\text { "Pd" }\end{array}$} & 17. Poor quality drug administered? & & & & \\
\hline & 18. Counterfeit drug administered? & & & & \\
\hline \multirow[t]{2}{*}{ Patient "Pa" } & 19. Non-compliance? & & & & \\
\hline & $\begin{array}{l}\text { 20. Self-medication with non-over-the } \\
\text { counter drug? }\end{array}$ & & & & \\
\hline
\end{tabular}

Age classification of patients was done according to the classification style adopted by the FDA which categorizes the age group into Neonates, Infants, Children and Adolescents ${ }^{(10)}$ as shown in Table 2 below.

Table 2. Age groups as suggested by FDA ${ }^{(10)}$.

\begin{tabular}{||l|l||}
\hline group & Age \\
\hline Neonates & birth up to 1 month \\
\hline Infants & 1 month up to 2 years \\
\hline Children & 2 up to 12 years \\
\hline Adolescents & 12 years up to 18 years \\
\hline
\end{tabular}

The medication error was classified into the phases at which the error occurs; Prescribing, Dispensing, Administration, Monitoring ${ }^{(1)}$.

For classification of drugs and herbals, the Anatomical Therapeutic Chemical (ATC) classification system was used, in which the active substances are divided into different groups according to the organ or system on which they act and their therapeutic, pharmacological and chemical properties $^{(11)}$

System Organ Class (SOC) was used for the classification of the adverse event which is the highest level of the hierarchy that provides the broadest concept for data retrieval ${ }^{(12)}$. 


\section{Results}

The total number of ICSR included in the current study was 2344 after the exclusion criteria were implied as shown in Figure 1.

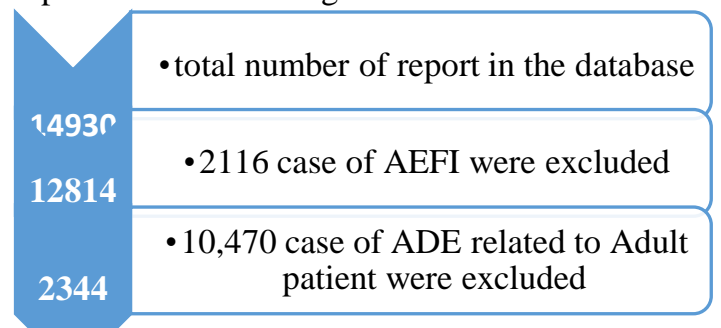

Figure 1. number of cases included and excluded in the study.
ADE: adverse drug events; AEFI: adverse events following immunization

The most gender of which AEs reported was males by 1237 (52.77\%), while AEs for females was 984 (41.98\%), while 123 reports did not specify the gender of the patient. The most Age group of which AEs reported was infants by 1239 (52.86\%), while AEs for children were 763 (32.55\%), adolescents 234 (9.98\%) and neonates 106 (4.52\%). Two reports did not specify the age group of the patient. The most province that contributes to reports of AEs was Baghdad (52.39\%), followed by Diyala (10.49\%). In addition, (10.45\%) of the reports were from Diwaniyah as shown in Table 3.

Table 3. Demographic distribution of individual case safety reports.

\begin{tabular}{|l|l|}
\hline Gender & ICSR count (\%) \\
\hline Male & $1237(52.77 \%)$ \\
\hline Female & $984(41.98 \%)$ \\
\hline N\A & $123(5.25 \%)$ \\
\hline Age of each group & Years (\%) \\
\hline Infants & $1239(52.86 \%)$ \\
\hline Children & $763(32.55 \%)$ \\
\hline Adolescents & $234(9.98 \%)$ \\
\hline Neonates & $106(4.52 \%)$ \\
\hline N\A & $2(0.09 \%)$ \\
\hline City & No. of reports received (\%) \\
\hline Baghdad & $1228(52.39 \%)$ \\
\hline Diyala & $246(10.49 \%)$ \\
\hline Diwaniyah & $245(10.45 \%)$ \\
\hline N\a & $153(6.53 \%)$ \\
\hline Nineva & $142(6.06 \%)$ \\
\hline Najaf & $100(4.27 \%)$ \\
\hline Basrah & $89(3.80 \%)$ \\
\hline Anbar & $43(1.83 \%)$ \\
\hline Erbil & $30(1.28 \%)$ \\
\hline Karbala & $23(0.98 \%)$ \\
\hline Kirkuk & $20(0.85 \%)$ \\
\hline Babylon & $16(0.68 \%)$ \\
\hline Thiqar & $4(0.17 \%)$ \\
\hline Wasit & $4(0.17 \%)$ \\
\hline Maysan & $1(0.04 \%)$ \\
\hline Grand Total & $2344(100.00 \%)$ \\
\hline NA: &
\end{tabular}

N/A: not available

It was found that anti-infective for systemic use drugs had the greatest number of reports by 1141 $(48.68 \%)$ followed by alimentary tract and metabolism drugs by $596(25.43 \%)$. The third-most reports were for antineoplastic and immunomodulating agents by $153(6.53 \%)$ as shown in Table 4. 
Table 4. Classification of drugs involved in the individual case safety reports.

\begin{tabular}{|l|l||}
\hline Type of ATC classification & AE count (\%) \\
\hline Anti-infective for systemic use & $1141(48.68 \%)$ \\
\hline Alimentary tract and metabolism & $596(25.43 \%)$ \\
\hline Antineoplastic and immunomodulating agents & $153(6.53 \%)$ \\
\hline Nervous system & $130(5.55 \%)$ \\
\hline Respiratory system & $92(3.92 \%)$ \\
\hline Systemic hormonal preparations, excluding reproductive hormones and insulins & $57(2.43 \%)$ \\
\hline Blood and blood-forming organs & $45(1.92 \%)$ \\
\hline Musculoskeletal system & $43(1.83 \%)$ \\
\hline Various ATC structures & $43(1.83 \%)$ \\
\hline Dermatological drugs & $17(0.73 \%)$ \\
\hline Cardiovascular system & $11(0.47 \%)$ \\
\hline Antiparasitic products, insecticides, and repellents & $7(0.30 \%)$ \\
\hline Sensory organs & $5(0.21 \%)$ \\
\hline Genitourinary system and reproductive hormones & $4(0.17 \%)$ \\
\hline Grand Total & $2344(100 \%)$ \\
\hline After & \\
\hline
\end{tabular}

After performing the $\mathrm{P}$ method for extraction of $\mathrm{ME}$ cases from ADR cases, the number of ADR cases was $1161(49.53 \%)$ while ME cases were 1183 $(50.47 \%)$.

Regarding the phases at which reaction occur, prescribing was the phase of greatest error (59.43\%), followed by administration phase $(39.98 \%)$, while monitoring phase errors were $(0.42 \%)$, and in the last dispensing phase errors were $(0.17 \%)$ as shown in Table 5.

Table 5. Adverse drug event type and phases of medication errors.

\begin{tabular}{||l|l|l||}
\hline Adverse drug events & Count & $\%$ \\
\hline Medication error & 1183 & $50.47 \%$ \\
\hline Adverse drug reactions & 1161 & $49.53 \%$ \\
\hline Grand Total & 2344 & $100.00 \%$ \\
\hline Phase of medication error & count & $\%$ \\
\hline Prescribing & 703 & $59.43 \%$ \\
\hline Administration & 473 & $39.98 \%$ \\
\hline Monitoring & 5 & $0.42 \%$ \\
\hline Dispensing & 2 & $0.17 \%$ \\
\hline Grand Total & 1183 & $100.00 \%$ \\
\hline
\end{tabular}

For the type of errors according to P method, selfmedication with non-over-the counter drug error is the most encountered one by $(44.28 \%)$, followed by documented hypersensitivity to the administered drug or drug class error by $(34.85 \%)$ and incorrect dose error by (10.69\%) as shown in Table 6. 
Table 6. Types of errors according to the $P$ method.

\begin{tabular}{|l|l|l|}
\hline Types of error & count & $\%$ \\
\hline Self-medication with the non-over-the counter drug? & 526 & $44.46 \%$ \\
\hline Documented hypersensitivity to the administered drug or drug class? & 414 & $35.00 \%$ \\
\hline Incorrect dose? & 127 & $10.74 \%$ \\
\hline Wrong indication? & 31 & $2.62 \%$ \\
\hline $\begin{array}{l}\text { Inappropriate prescription according to characteristics of the patient (age, } \\
\text { sex, pregnancy, other)? }\end{array}$ & 26 & $2.20 \%$ \\
\hline Poor quality drug administered? & & \\
\hline $\begin{array}{l}\text { Drug administration error (timing, rate, frequency, technique, preparation, } \\
\text { manipulation, mixing)? }\end{array}$ & 20 & $1.69 \%$ \\
\hline Counterfeit drug administered? & $1.69 \%$ \\
\hline Necessary medication not given? & 5 & $0.42 \%$ \\
\hline $\begin{array}{l}\text { Inappropriate prescription for patient's clinical condition (renal failure, } \\
\text { hepatic failure ...), or underlying pathology? }\end{array}$ & 2 & $0.42 \%$ \\
\hline Labeled drug-drug interaction? & 5 & $0.17 \%$ \\
\hline Non-compliance? & 2 & $0.17 \%$ \\
\hline Incorrect drug administration route? & 2 & $0.17 \%$ \\
\hline Incorrect drug dosage formulation administered? & 1 & $0.08 \%$ \\
\hline Incorrect storage of drugs? & 1 & $0.08 \%$ \\
\hline Total & 1 & $0.08 \%$ \\
\hline
\end{tabular}

The most common ADE was related to skin and subcutaneous tissue disorders $(28.23 \%)$, followed by gastrointestinal disorders $(25.87 \%)$. In addition, $(10.82 \%)$ of the ADE were for metabolism and nutrition disorders as shown in Table 7. From the skin and subcutaneous tissue disorders, about $(47.83 \%)$ were related to penicillin allergy.

Table 7. Adverse drug event resulted from medication error classified by system organ class SOC

\begin{tabular}{|l|l|l||}
\hline Type of Adverse event (SOC) & Count & $\mathbf{\%}$ \\
\hline Skin and subcutaneous tissue disorders & 334 & $28.23 \%$ \\
\hline Gastrointestinal disorders & 306 & $25.87 \%$ \\
\hline Metabolism and nutrition disorders & 128 & $10.82 \%$ \\
\hline Immune system disorders & 105 & $8.88 \%$ \\
\hline Respiratory, thoracic and mediastinal disorders & 81 & $6.85 \%$ \\
\hline General disorders and administration site conditions & 78 & $6.59 \%$ \\
\hline Injury, poisoning, and procedural complications & 48 & $4.06 \%$ \\
\hline Nervous system disorders & 32 & $2.70 \%$ \\
\hline Cardiac disorders & 16 & $1.35 \%$ \\
\hline Infections and infestations & 14 & $1.18 \%$ \\
\hline Renal and urinary disorders & 6 & $0.51 \%$ \\
\hline Hepatobiliary disorders & 5 & $0.42 \%$ \\
\hline Musculoskeletal and connective tissue disorders & 5 & $0.42 \%$ \\
\hline Psychiatric disorders & 5 & $0.42 \%$ \\
\hline Congenital, familial and genetic disorders & 4 & $0.34 \%$ \\
\hline Investigations & 4 & $0.34 \%$ \\
\hline Vascular disorders & 4 & $0.34 \%$ \\
\hline Blood and lymphatic system disorders & 3 & $0.25 \%$ \\
\hline Eye disorders & 3 & $0.25 \%$ \\
\hline Ear and labyrinth disorders & 1 & $0.08 \%$ \\
\hline Gastrointestinal signs and symptoms & 1 & $0.08 \%$ \\
\hline Grand Total & $\mathbf{1 1 8 3}$ & $\mathbf{1 0 0 . 0 0 \%}$ \\
\hline SOC system & 5 & \\
\hline
\end{tabular}

SOC: system organ class. 


\section{Discussion}

Once a drug is approved to be sold in the market, it will be used by thousands of patients rather than those numbers used during the trials. Thus, the information gained during the trials considered incomplete and more information about the effect of these products will appear once it is used by a lot of patients and this creates a powerful tool for reaching the ultimate goal of safe and effective use of drugs ${ }^{(4)}$. The results of the current study revealed that males and infants encountered the most reports by $(52.77 \%)$ and $(52.86 \%)$ respectively as shown in Table 3 . In one Iindian study, more than half of the ADE reports were for male $(58.5 \%)$ and infants $(53.2 \%)^{(13)}$. As for the provincese contribution to reports, it was found that Baghdad provinces contribute to the most of reports $(52.39 \%)$ as compared to others as shown tin Table 3 , this is expected as Baghdad is the capital of Iraq and represents the center of most health care institutes and have the largest number of populations among the other provinces. Regarding the ATC classification system, Anti-infective for systemic use was $(48.68 \%)$ of the total cases in this study as shown in Table 4. A study in Turkey revealed that the rate of antibiotic use was $(70.8 \%)$ in pediatric patients, from it, unnecessary antibiotic prescription was the most common cause for inappropriate antibiotic use $(51.9 \%)^{(14)}$. In two studies conducted in South Carolina and Nigeria, both revealed that the most reported therapeutic agent that has been associated with hospital $\mathrm{ME}$ in children is antimicrobials (between $(22.9 \%)^{(15)}$ and $(50.3 \%)^{(16)}$ ) respectively. The prevalence of medication errors that were found in this study was $(50.47 \%)$ which are preventable in comparison with $(49.53 \%)$ that of ADRs cases that are non-preventable as shown in Table 5 and this draws big attention to supply recommendations to reduce these preventable incidences to improve health and safety. In one Ethiopian study that included 1251 patients, it was found that the prevalence of medication errors was $(62.7 \%)^{(17)}$. Prescribing phase error were the most prevelance one according to the result of current study as shown in Table 5. Richard. et. al, found that education should be targeted to all doctors who have prescribing responsibility for children. Because so many doctors care for children as part of their job, this should begin at the undergraduate level and continue in specialty training and as part of induction processes ${ }^{(18)}$. According to $\mathrm{P}$ method, self-medication with non-over-the counter drug error was the most encountered one by $(44.28 \%)$ as shown in Table 6, as this error involve any case of patients took medications without counselling physician. From these errors, (sagwa) poisoning was in the lead and it was considered to be fit in this category for this study. Sagwa is a folk remedy prepared from a mixture of boiled animal parts of urchin, tar, drug (Diphenoxylate and Atropine), rose water, and cow feces (19). One study in Iraq concluded that there is a significant morbidity and mortality caused by (sagwa) use in children with acute gastroenteritis ${ }^{(20)}$. The most comon type of $\mathrm{ADE}$ due to $\mathrm{ME}$ was related to skin and subcutaneous tissue disorders which include rash, erythema, urticaria as related to allergy and mostly because they did not perform sensitivity test. From these, about $(47.83 \%)$ were related to penicillin allergy. Infants must be tested for Penicillin allergy before administering of Penicillin for the first time. One study in Rochester which is a city in the U.S., children were more likely to have a positive penicillin skin test $(\mathrm{P}<.0001)$ compared with adults (21). Priyadharsini. et. al, found in their study of ADR in pediatric patients that rashes and urticaria were the most common type of ADR (37\%) followed by fever, anaphylactic shock, vomiting, chills, and rigors ${ }^{(22)}$. Also, a study in Saudi Arabia found that skin associated ADRs were most frequent in both retrospective and prospective studies (37\%) and $(42.9 \%)$ followed by gastrointestinal tract $(33.3 \%)$ and $(24.5 \%)$ respectively ${ }^{(23)}$. The limitation of this study was the lack of completed report information like the absence of patient history in many reports, . Also, the accuracy of many reports was not accurate. Finally, lower reporting rate for health care professionals other than pharmacists.

\section{Conclusions and Recommendations}

The result of the present study revealed that medication errors contribute significantly to adverse drug event among patients under 18 years old. Further investigations must be done and there must be a periodic analysis of the reports that are submitted to the Iraqi Pharmacovigilance Center. Activities to decrease medication errors must be adopted including establishing programs and workshops in pediatric hospitals about diseases and their first-line treatment, providing a chart for physicians and pharmacists that include the recommended doses in relation to the weight and height of patients, encouraging the pharmacists to participate in medication decision during morning tours, and encourage the pharmacist to educate parents and medical staff about the correct way of administrating the medications. 


\section{References}

1. Benabdallah G, Alj L, Benkirane R, Bencheikh R, Cousins D, Olsson S, et al. WHO Guideline: Reporting and Learning Systems for Medication Errors: The Role of Pharmacovigilance Centres. 2015. 939 p.

2. Department of Health. Pharmacy in England: Building on Strengths-Delivering the Future. UK Dep Heal [Internet]. 2008;69. [last accessed 2020 Feb 15]. Available from: http://scholar.google.com/scholar?hl=en\&btnG $=$ Search $\& q=$ intitle:Pharmacy + in + England $+B u$ ilding+on+strengths+?+delivering+the+future\# 0\%5Cnhttp://archive.communitypharmacyhum ber.org.uk/ERHLPC/www.lpc-

online.org.uk/bkpage/files/145/resources/deliv ering_the_futur

3. Assiri GA, Shebl NA, Mahmoud MA, Aloudah $\mathrm{N}$, Grant E, Aljadhey $\mathrm{H}$, et al. What is the epidemiology of medication errors, errorrelated adverse events and risk factors for errors in adults managed in community care contexts? A systematic review of the international literature. BMJ Open. 2018;8(5).

4. Morimoto T, Gandhi K, Sege A, T C Hsieh BD. Adverse drug events and medication errors. BMJ Qual Saf [Internet]. 2004;13(13):306-315.

5. World Health Organization (WHO). Pharmacovigilance: ensuring the safe use of medicines. World Health [Internet]. 2004;16.[last accessed 2020 Feb 18]. Available from: http://pvtoolkit.org/toolkit/readers/pv_ensuring _safe_medicine_use.pdf

6. Dalmolin GR dos S, Rotta ET, Goldim JR. Medication errors: Classification of seriousness, type, and of medications involved in the reports from a university teaching hospital. Brazilian J Pharm Sci. 2013;49(4):793-802.

7. Davis T. Paediatric prescribing errors. Arch Dis Child [Internet]. 2011 May 1;96(5):489 LP 491. [last accessed 2020 Feb 23]. Available from: http: //adc .bmj .com / content /96 /5 / 489.

8. Gonzales K. Medication Administration Errors and the Pediatric Population: A Systematic Search of the Literature. J Pediatr Nurs Nurs Care Child Fam [Internet]. 2010 1;25(6):555565..

9. K. Abd A, J. Kadhim D, M. Younus M. Assessment of Causality, Severity and Seriousness of Adverse Event Following Immunization in Iraq: A Retrospective Study Based on Iraqi. Iraqi $\mathbf{J}$ Pharm Sci. 2019;28(2):142-150.
10. Food and Drug Administration. General clinical pharmacology considerations for pediatric studies for drugs and biological products. 2014;(December):1-25.

11. World Health Organization. Guidelines for and DDD assignment. WHO collaborating centre. 2013. 1-284 p.

12. Medical Dictionary for Regulatory Activities. Introductory Guide MedDRA Version 15.1. 2012;(September):1-78. Available from: https://www.meddra.org/sites/default/files/guid ance/file/intguide_13_1_english.pdf\%0Ahttp:// www.meddra.org/sites/default/files/guidance/fi le/intguide_15_1_English_0.pdf

13. Nikhithasri $P$, Ramya $M$, Kishore $P$. Assessment of Medication Errors in Pediatricinpatient Department of a Private Hospital. Int J Curr Pharm Res. 2017;9(6):70.

14. Ergül AB, Gökçek İ, Çelik T, Altuner Torun Y. Assessment of inappropriate antibiotic use in pediatric patients: Point-prevalence study. Turk Pediatr Ars. 2018;53(1):17-23.

15. Quidley A, Cox C, Caulder C, Bookstaver B, Bair J, Bennett C. Nighttime and Weekend Medication error rates in an inpatient pediatric population. Ann Pharmacother. 2010 1;44:1739-46.

16. Ameer A, Dhillon S, Peters $M$, Ghaleb $M$. Systematic literature review of hospital medication administration errors in children. Integr Pharm Res Pract. 2015;153.

17. Baraki Z, Abay M, Tsegay L, Gerensea H, Kebede A, Teklay H. Medication administration error and contributing factors among pediatric inpatient in public hospitals of Tigray, northern Ethiopia. 2018;1-8.

18. McLellan L, Dornan $T$, Newton $P$, Williams SD, Lewis P, Steinke D, et al. Pharmacist-led feedback workshops increase appropriate prescribing of antimicrobials. J Antimicrob Chemother. 2016;71(5):1415-25.

19. Riyadh M . Kadhim Nassrawi . Acute Lead Encephalphathy due to ingestion of certain herbal folk remedies rural area in Iraq. International Journal of Current Research 2018;10 ( 12),:76422-76425.

20. M Shukur A, I Alezzi J, J Kadhim T. Morbidity and Mortality Associated with Community used Herbal (sagwa)use in Children with Acute Gastroenteritis in Diyala Governorate. Diyala J Med. 2019;17(2):92-106. 
21. Tanzi MG. New recommendations released for allergic, respiratory conditions. Pharm Today [Internet]. 2017;23(2):22-23.

22. Priyadharsini R, Surendiran A, Adithan C, Sreenivasan S, Sahoo FK. A study of adverse drug reactions in pediatric patients. J Pharmacol Pharmacother . 2011;2(4):277-280.
23. Khan LM, Al-Harthi SE, Saadah OI. Adverse drug reactions in hospitalized pediatric patients of Saudi Arabian University Hospital and impact of pharmacovigilance in reporting ADR. Saudi Pharm J. 2013;21(3):261-266.

\section{(2) (1)}

Baghdad Iraqi Journal Pharmaceutical Sciences by bijps is licensed under a Creative Commons Attribution

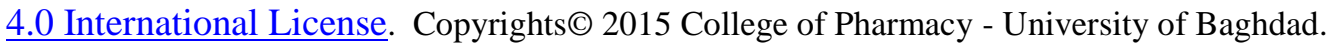

